\title{
SHARENTING: VIOLAÇÃO DO DIREITO DE IMAGEM DAS CRIANÇAS E ADOLESCENTES PELOS PRÓPRIOS GENITORES NA ERA DIGITAL
}

\author{
Luiza Gabriella Berti ${ }^{1}$ \\ Zulmar Antonio Fachin ${ }^{2}$
}

\section{RESUMO}

O tema da pesquisa é o fenômeno conhecido como sharenting, caracterizado pela violação ao direito de imagem das crianças e dos adolescentes pelos próprios genitores, com a utilização das mídias sociais. $\mathrm{O}$ objetivo do estudo é refletir sobre o grau de incidência desse fenômeno, em especial porque o tempo atual é o da Era Digital. Para tanto, emprega-se neste estudo o método hipotético-dedutivo, com a utilização de livros e artigos científicos publicados em revistas especializadas e em sites. Conclui-se que o uso desregrado do sharenting fere o direito à imagem de crianças e adolescentes, considerado direito da personalidade.

PALAVRAS-CHAVE: Direito à imagem; Direitos da personalidade; Direito fundamental; Poder familiar; Sharenting

\section{SHARENTING: INFRINGEMENT OF CHILDREN AND ADOLESCENTS IMAGE RIGHTS BY THEIR GENITORS IN THE DIGITAL AGE}

\begin{abstract}
The research theme is the phenomenon known as sharenting, characterized by the violation of the image rights of children and adolescents by the parents on social media. The objective of the study is to reflect on the degree of incidence of this phenomenon, especially by the Digital Era. Therefore, the hypothetical-deductive method is used in this study, with the use of books and scientific articles published in specialized magazines and on websites. It is concluded that the unruly use of sharenting violates the right to the image of children and adolescents, a right of the personality.
\end{abstract}

KEYWORDS: Right the image; Personality rights; Fundamental right; Family power; Sharenting.

\section{INTRODUÇÃO}

O presente trabalho tem como enfoque o fenômeno intitulado de sharenting, que vem das junções das palavras "compartilhar" e "parentalidade" na língua inglesa, caracterizado

\footnotetext{
${ }^{1}$ Mestranda no Programa de Pós-graduação Stricto Sensu em Ciências Jurídicas da UNICESUMAR. Graduada em Direito pela Universidade Paranaense (UNIPAR). Estagiária de pós-graduação da 6a Promotoria de Justiça de Umuarama-PR.

${ }^{2}$ Doutor em Direito Constitucional (UFPR). Mestre em Direito (UEL) e Ciência Política (UEL). Professor na UNICESUMAR (Programa de Doutorado e Mestrado), UEL e Escola de Direito das Faculdades Londrina.
} 
pelo compartilhamento excessivo e irresponsável de imagens, mas também, eventualmente, de dados e informações por parte dos pais acerca de seus filhos.

Esse fenômeno é potencializado no espaço temporal da Era Digital, caracterizada, sobremaneira, pela presença das mais variadas tecnologias no dia-a-dia das pessoas. Assim, é comum que nos últimos anos o aumento da utilização das então chamadas mídias sociais, haja vista que esta é uma das consequências da inclusão da modernidade na vida alheia, entretanto nem sempre essas são utilizadas de forma diligente.

Por conseguinte, o direito à imagem tratado neste estudo se refere à imagem filmada, fotografa, esculpida. Não contempla, então, a imagem sinônimo de reputação, de prestígio que a pessoa pode desfrutar no meio social. Considera-se o direito à imagem como direito da personalidade. Por outro lado, trata da violação, pelos próprios genitores, do direito à imagem de criança e adolescente, por meio das plataformas digitais, o que é conhecido como sharenting.

Justifica-se a presente pesquisa pelo fato de que tanto as crianças quanto os adolescentes seguem orientações dos seus genitores. Esses devem ter elevada cautela nas plataformas digitais, visto que a exposição pública dos seus descendentes pode configurar atos ilícitos. Sendo assim, esta pesquisa pretende averiguar se os próprios pais têm tido ou não cautela na orientação dos filhos, tendo em vista que se considera que tal hábito fere o direito à imagem dos infantojuvenis e tem o condão de influenciar diretamente no processo de desenvolvimento da personalidade.

A hipótese da pesquisa está em saber se os genitores tem legitimidade para conduzir uma criança ou um adolescente a atuar intensamente em redes sociais, em face do risco de violações de seus direitos. Em outras palavras, busca compreender se o uso do sharenting, nos moldes em que vem ocorrendo, viola direitos de crianças e adolescentes, em especial a sua imagem, considerada direito da personalidade.

\section{FAMÍLIA, CRIANÇA E ADOLESCENTE NA CONSTITUIÇÃO FEDERAL}

A família é um dos agrupamentos humanos que sempre está nos debates acalorados das mais diversas áreas. No Direito não é diferente, tem-se até mesmo um ramo específico para seu estudo, caracterizado pela sua dinamicidade e rápida transformação.

Assim, reconhece-se que a família passou por mudanças drásticas em razão de certos acontecimentos histórico-sociais, tais como a Revolução Industrial, o movimento feminista, a 
inclusão da mulher no mercado de trabalho, a descoberta de novas formas de reprodução humana e o surgimento do Estado Democrático de Direito ${ }^{3}$. Por ser uma reflexão da própria sociedade na qual está inserida, a família "sofreu os influxos desses movimentos, passando por uma verdadeira transição paradigmática que lhe ocasionou mudanças estruturais e funcionais" (CALDERÓN, 2013, p. 06).

Necessário, também, citar a importância da afetividade ${ }^{4}$ para que se passasse a exaltar uma nova visão do núcleo familiar. Anteriormente, percebia-se que os filhos eram criados por e para seus genitores, ligados ao que era então chamado de pátrio poder e, nos dias atuais, transformou-se no poder familiar, definido como "[...] um conjunto de prerrogativas legais reconhecidas aos pais para a criação, orientação e proteção dos filhos menores de 18 (dezoito) anos" (RAMOS, 2015, p. 43). Por isso, tem-se falado em responsabilidade parental, poder parental, autoridade parental ou pátrio dever.

Neste sentido, a família, estrutura já multicelular, não é mais focada tão somente naquilo que, a priori, seria entendido como seu provedor, o pai, a partir de uma estrutura paternalista, mas, atualmente, foca-se em todos os membros que a compõem a fim de que alcancem aquilo que os enobreça mais ainda como seres humanos. Ou seja, a família tem como um de seus maiores objetivos, senão o maior, a realização daqueles que dela fazem parte.

\begin{abstract}
Assim sendo, a família, embora tenha ampliado, com a Carta de 1988, o seu prestígio constitucional, deixa de ter valor intrínseco, como instituição capaz de merecer tutela jurídica pelo simples fato de existir, passando a ser valorada de maneira instrumental, tutelada à medida que - e somente à exata medida que - se constitua em núcleo intermediário de desenvolvimento da personalidade dos filhos e de promoção da dignidade de seus integrantes (TEPEDINO, 2020, p. 03).
\end{abstract}

Ademais, não se tem mais uma família formada apenas a partir do casamento, civil ou religioso com efeitos civis. Tem-se também uniões estáveis e famílias monoparentais, dentre tantas outras formas que vêm sendo acolhidas pela doutrina e jurisprudência, em especial por conta de a Constituição Federal de 1988 trazer um rol exemplificativo no seu art. 226, o qual frisa a proteção desse agrupamento (BRASIL, 1988).

\footnotetext{
${ }^{3}$ A Lei no 6.515 de 1977, mais conhecida como Lei do Divórcio, também influenciou demasiadamente para sua mudança.

${ }^{4}$ A afetividade, apesar de não ser um princípio expressamente previsto na Constituição Federal, pode ser extraída do capítulo atinente à família, criança, adolescente, jovem e idoso, assim como do princípio da dignidade da pessoa humana.
} 
Nesse contexto, passou-se a falar em constitucionalização das relações privadas, isto é, a interpretação do direito privado de acordo com os princípios e os direitos fundamentais contidos no texto constitucional, sem retirar a autonomia da vontade que lhe é característica, mas levando-se em consideração a dignidade da pessoa humana. Portanto, a

constitucionalização do direito civil fez com que o ponto de referência axiológicointerpretativo seja a Constituição. É dizer: mantém-se a autonomia científica do sistema civilista, mas se reconhece que seus postulados, princípios e regras são redimensionados a partir dos valores constitucionais, mormente no que se refere à tutela dos direitos fundamentais (JABORANDY; GOLDHAR, 2018, p. 485).

Essas metamorfoses influenciaram diretamente para que houvesse uma "repersonalização contemporânea das relações familiares", a qual "[...] retoma o itinerário da afirmação da pessoa humana como objeto central do direito" (LÔBO, 2016, p. 22). De igual maneira, vislumbraram-se mudanças sobre o olhar para com as crianças e os adolescentes, saindo da "menoridade" e integrando a doutrina da proteção integral.

Vale destacar que esses sujeitos recebem atenção diferenciada no texto constitucional (art. 227), abarcando a proteção integral da criança e do adolescente e a primazia na eficácia de seus direitos. Além disso, acomoda a responsabilidade tríplice da família, da sociedade e do Estado de participarem ativamente das "[...] mudanças e proteções da realidade infantojuvenil nacional, com vista a lhes proporcionar sempre as melhores condições de desenvolvimento e respeito a dignidade humana" (OLIVEIRA, 2008, p. 6627). Partindo do entendimento de que são pessoas em condição peculiar de constante evolução, de acordo com a Convenção das Nações Unidas sobre os Direitos da Criança ${ }^{5}$.

[...] j) Já não se trata de incapazes, meias-pessoas ou pessoas incompletas, mas sim pessoas completas, cuja particularidade é que estão em desenvolvimento. Por isso se reconhecem todos os direitos que têm todas as pessoas, mais um plus de direitos específicos precisamente por reconhecer-se que são pessoas em peculiar condição de desenvolvimento (SARAIVA, 2009, p. 63).

Nesse campo evolutivo, foi promulgada a Lei no 8.069 , de 13 de julho de 1990, mais conhecida como Estatuto da Criança e do Adolescente, feita sob égide da proteção integral, de modo que assegura ao público infantojuvenil direitos fundamentais disciplinados no título II (BRASIL, 1990), a englobar a ideia de que estão em construção de sua individualidade, além

\footnotetext{
${ }^{5}$ Promulgada no Brasil através do Decreto no 99.710, de 21 de novembro de 1990.
} 
de titulares daqueles empalhados pelo texto constitucional por conta do simples fato de serem seres humanos. Logo, nota-se

\begin{abstract}
a importância que foi dada à criança, ao adolescente e ao jovem, uma vez que o ECA estabelece serem eles titulares dos direitos fundamentais inerentes à pessoa, garantindo-lhes proteção integral. Dessa forma, encontram-se em situação privilegiada em comparação aos adultos. A lei assegura também as melhores condições para que o desenvolvimento (físico, mental, moral, espiritual e social) não somente ocorra, mas que se faça em condições de liberdade e dignidade. Em conformidade com a princípio da igualdade, o Estatuto proíbe que criança ou adolescente sofra qualquer tipo de discriminação (MORAES, 2019, p. 34).
\end{abstract}

Por sua vez, o Estatuto dá ênfase à proteção integral, assim como também reproduz a responsabilidade tríplice retratada (art. 4으). Desse modo, percebe-se a essencialidade da família para as crianças e os adolescentes, pois, em que pese estes comecem a fazer parte de outros agrupamentos humanos cada vez mais cedo, na grande maioria dos casos, é nessa que os indivíduos têm o seu primeiro contato antes de integrarem "o mundo exterior".

Sendo assim, além da afetividade, existem outros princípios imprescindíveis para o direito das famílias, a exemplo da solidariedade familiar, igualdade entre os filhos, igualdade entre os cônjuges e companheiros, melhor interesse da criança, do adolescente e do jovem, função social da família, proteção ao idoso, pluralidade familiar, livre planejamento familiar e parentalidade responsável. Especificamente, este estudo dá atenção aos do melhor interesse da criança, do adolescente e do jovem e da parentalidade responsável.

O primeiro, relaciona-se ao fato de que, no caso em concreto, deve-se tomar a decisão, seja ela jurídica, ou, simplesmente, concernente ao cotidiano, que melhor atenderá aos interesses e direitos dos vulneráveis. Portanto, salienta Gustavo Tepedino que "No ambiente familiar, essa tarefa se faz ainda mais importante, impondo-se à ordem jurídica mapear os indivíduos vulneráveis, oferecendo-lhes instrumentos para desenvolver suas potencialidades e superar sua condição de vulnerabilidade" (2020, p.18).

Enquanto isto, a parentalidade responsável conceitua-se "[...] como a obrigação que os pais têm de prover a assistência moral, afetiva, intelectual, material e também a própria orientação sexual dos filhos" (ROSA; CARDIN, 2012, p. 20). A observância de ambos, além de outros, integra a responsabilidade parental que os genitores têm no tocante aos filhos, porém, verifica-se que, em algumas situações, as quais serão pormenorizadas adiante, não vêm sendo levados em conta. Valéria Silva Galdino Cardin, Marcela Gorete Rosa Maia Guerra e Andréia Colhado Gallo Grego Santos trazem apontamentos pertinentes de como a 
valorização do capital em detrimento das relações humanas influencia na parentalidade responsável asseverando que:

O homem, egoísta, crê em direitos absolutos e não reconhece suas responsabilidades, e assim não exerce o devido dever de cuidado em relação ao menor, frágil, carente do devido amparo material e muitas vezes do amparo intelectual para o desenvolvimento pleno de sua personalidade. $\mathrm{O}$ culto ao capital reveste nas pessoas o desejo pela ostentação e pela riqueza, que tendem a se atrair umas pelas outras por valores materiais, e muitas vezes usam de subterfúgios para estabelecer um vínculo filial com uma pessoa em razão do seu dinheiro. Os ideais pútridos do capitalismo sobressaem aos valores do bem comum familiar, colocando os direitos de personalidade das crianças, os seres completamente vulneráveis nestas relações, em risco (2014, p. 137-138).

Desse modo, os pais, muitas vezes, não se pautam nos direitos de seus filhos e o que lhes trarão maiores benefícios, como é o caso da exposição reiterada da sua imagem nas mídias sociais, movidos pelo desejo de aceitação social em forma de likes ${ }^{6}$ e pela liquidez dos comportamentos sociais, guiados por interesses próprios e, ocasionando, o que hoje é intitulado de sharenting, sobre o qual o item posterior retratará.

\section{O FENÔMENO SHARENTING COMO VIOLADOR DO DIREITO DE IMAGEM}

Atualmente, o mundo vive na chamada Era Digital e as tecnologias estão cada vez mais intrínsecas ao cotidiano das pessoas. Valéria Perasso (2016, online) dispõe que existiram três grandes revoluções industriais, de maneira que a terceira delas é referente ao fenômeno citado, ocorrida em meados do século XX, com a chegada da eletrônica, da tecnologia de informação e das telecomunicações. Com isso, adveio, a utilização das redes sociais, por meio das quais os indivíduos conectam-se entre si compartilhando informações, conteúdos, vídeos, fotos etc., o que facilita o intercâmbio humano e faz com que as barreiras entre os povos sejam derrubadas.

À vista disso, Ciribelli e Paiva (2011, p. 65) entendem que:

O sucesso das redes sociais na internet dá-se pela liberdade de expressão e realidade dos conteúdos postados. Por não estarem cara a cara, há uma entrega maior dos usuários quanto à exposição de seus sentimentos e opiniões que são postados e discutidos na rede.

\footnotetext{
${ }^{6}$ Palavra também de origem inglesa que, na atualidade, angariou novo significado, a qual se identifica em forma de "curtidas", por seus usuários, nos conteúdos postados em determinadas redes sociais.
} 
Nessas redes os internautas divulgam fatos relacionados ao seu dia a dia, acontecimentos pessoais importantes, reuniões entre amigos e, inclusive, muitos acabam fazendo das redes sociais a sua profissão. Nesse campo, tem-se observado, por sua vez, que as postagens dos usuários não estão apenas relacionadas a si, mas acabam envolvendo as suas famílias, pois, como mencionado, podem tratar-se de fatos pessoais.

Logo, consoante o pesquisador Juan Ángel Jódar Marín (2010, p. 07, tradução nossa) “o usuário deixa de ser um mero receptor de informação, consumidor sedentário das mídias tradicionais e adota um papel ativo frente a uma oferta completa e heterogênea de conteúdos que este poderá selecionar de acordo com suas possibilidades"?.

Ocorre que, certas vezes, as divulgações envolvem crianças e adolescentes, não sendo raro verificar que isto se dá pelos próprios genitores, que não se dão conta do perigo que podem estar a sujeitar seus filhos, bem como vir a ferir seus direitos da personalidade, em especial o direito à imagem dessas pessoas. Esse fenômeno de exposição é intitulado de sharenting, o qual terá explicação pormenorizada adiante. Assim, de acordo com Stacey B. Steinberg:

[...] "sharenting", um termo usado para descrever o fenômeno de compartilhamento, online, de detalhes da vida dos filhos por parte dos pais, deve ser um assunto discutido frequentemente na criação da prole, tendo em vista que isto traz à tona 0 embate entre os direitos dos filhos e dos pais (2017, p. 842, tradução nossa) ${ }^{8}$.

Neste sentido, para Coutinho (2019, p. 32), sharenting "corresponde a prática dos pais em partilhar informações e imagens dos filhos nas redes sociais de maneira abundante e detalhada".

Outrossim, destaca Fernando Büscher von Teschenhausen Eberlin (2017, p. 258) que "A ideia de sharenting, também, abarca as situações em que os pais fazem a gestão da vida digital de seus filhos na internet, criando perfis em nome das crianças em redes sociais e postando, constantemente, informações sobre sua rotina”. Ainda sobre esta prática seguem reflexões de Sílvia Felipe (2019, online):

\footnotetext{
${ }^{7}$ El usuario deja de ser un mero receptor de información, consumidor sedentario de los medios tradicionales, y adopta un papel activo frente una oferta completa y heterogénea de contenidos que él mismo puede seleccionar según sus necessidades.

${ }^{8}[\ldots]$ "sharenting", a term used to describe the ways many parents share details about their children's lives online, must be a central part of child-rearing discourse and legal analysis of the conflict between children's rights and parental rights.
} 
A prática de compartilhar fotos e informações acerca dos filhos e do exercício da parentalidade passou a ser conhecida como "sharenting”, termo criado da junção das palavras em inglês "share" (compartilhar) e "parenting" (criação, cuidado parental). Entende-se como sharenting, portanto, a prática reiterada de compartilhamento, pelos pais ou responsáveis, de imagens e informações sobre a vida do filho e de seu cotidiano (escolas, atividades extras, viagens, etc). [...] O sharenting, por si só, possui aspectos jurídicos na própria relação entre a criança e quem posta a sua imagem ou suas informações. Fato é que, ainda que quem publique na rede tome alguns cuidados - como fazer posts apenas em ambientes privados supondo que isso seja realmente possível na internet - a imagem da criança permanecerá na rede mundial de computadores por muitos anos, podendo causar a ela prejuízos ou embaraços em algum momento de sua vida.

A veiculação constante de imagens, dados e informações dos filhos pelos genitores nas redes sociais é mais comum do que se imagina. Necessita-se, pois, por parte dos responsáveis legais dos absolutamente ou relativamente incapazes, terem diligência quanto à exposição da imagem e também da vida privada de seus filhos, pautando-se nos possíveis danos que seus atos refletirão em sua integridade e personalidade. Para Zulmar Antônio Fachin, a imagem, tamanha é a sua importância, acaba sendo uma " [...] manifestação de sua própria personalidade, do seu ser. É a imagem que o apresenta na vida social, em todos os momentos, onde quer que esteja" (1999, p. 50). Nesse mesmo sentido, Jacqueline Sarmento entende que a imagem é a própria externalização da personalidade. É a concretização dessa abstração física e moral. Não se reduz ao rosto, às feições de cada um, mas inclina-se por todos os modos de ser físicos e psíquicos do homem (2000, p. 71).

Portanto, além do dever de exercício da parentalidade responsável, é necessário ter em vista o melhor interesse da criança e do adolescente, ou seja, em ambientes que suas figuras estejam envolvidas, ainda mais no âmbito da internet, onde há armazenamento de dados pela rede e dúvidas quanto ao seu destino, esses precisam de olhar diferenciado sob a premissa de que são pessoas em desenvolvimento de seu físico, psíquico, intelectual, social e sua moral. Por conseguinte,

proteger o filho das ameaças externas é um objetivo de todos os pais. Não falar com estranhos, não aceitar coisas, não pegar caronas com desconhecidos etc., são instruções/recomendações que toda criança ouve exaustivamente. Os pais sempre temeram os "estranhos". Todavia, parece que essa noção de perigo se esvai no ambiente virtual, haja vista a exposição supramencionada. Aliás, com relação à exposição no ambiente virtual, as pessoas têm opiniões diferentes. Embora os pais gostem de exibir seus filhos, estes muitas vezes podem não concordar (LISBOA; CHRISTÓFARO, 2018, p. 09). 
Lembre-se ainda que a atual Constituição Federal foi a responsável por adotar, efetivamente, a doutrina da proteção integral da criança e do adolescente em território nacional (art.227), além do direito à infância ser um direito social (art. 6º). Neste sentido, o texto constitucional dispôs diretriz que versa a respeito à prioridade na efetivação dos direitos das crianças e dos adolescentes, especialmente pela condição peculiar de essas pessoas estarem em constante desenvolvimento. Então, “deverão as crianças e adolescentes ter todas as oportunidades e faculdades para potencializarem o seu estado físico, mental, moral, espiritual e social, em condições de liberdade e dignidade [...]” (ROSSATO, 2019, p. 80).

Assim, “[...] todas as crianças e adolescentes, sem distinção, desfrutam dos mesmos direitos e sujeitam-se a obrigações compatíveis com a peculiar condição de desenvolvimento que desfrutam" (SARAIVA, 2009, p. 85). Inclusive, o Estatuto abrange o "direito ao respeito", de maneira que protege a integridade física, psíquica e moral das crianças e dos adolescentes, bem como engloba a preservação de sua imagem, identidade, autonomia, valores, ideias, crenças, espaços e objetos pessoais (arts. 17 e 18). Neste contexto, vislumbrase, então, que "Todo ser humano tem direito ao respeito [...]. Contudo, em relação às crianças e adolescentes, esse direito surge potencializado, pois os danos que podem surgir em razão de sua inobservância são irreversíveis" (ROSSATO; LÉPORE; SANCHES, 2014, p. 145).

Um exemplo notório e recente de caso de sharenting ocorrido no Brasil em 2020 foi o da menina Bel. À época, com 13 anos, ela tinha um canal da plataforma de compartilhamento de vídeos Youtube, coordenado por seus genitores, com mais de 7 milhões de inscritos. Seus espectadores detectaram que nos últimos vídeos disponibilizados a adolescente parecia estar constrangida e desconfortável, submetida a atividades que não tinham mais correlação com a sua idade (RIBEIRO, 2020).

Logo, sensibilizados pela situação, a questão virou um dos assuntos mais comentados na rede social Twitter, sendo criada a hashtag "Salvem Bel para Meninas". A posteriori, tanto o Conselho Tutelar quanto o Ministério Público foram acionados para averiguar essa circunstância e seus vídeos foram retirados da plataforma, pois, em alguns dos conteúdos excluídos, a adolescente foi obrigada a lamber mistura de bacalhau com leite, quebrar um ovo em sua cabeça e ouviu de sua mãe que seria adotada (MANDELLI, 2020).

Por sua vez, vislumbra-se que o poder familiar dos pais em relação aos filhos não é ilimitado e tão pouco deve ser exercido autoritariamente. O que se quer dizer é que, apesar de as crianças e adolescentes terem os deveres de respeito e obediência para com os genitores, é 
essencial que haja diálogo entre ambos, quando possível, em especial quanto à veiculação de suas imagens nas mídias sociais, como uma forma de exercício gradual de seus direitos fundamentais e direitos da personalidade.

Portanto, o sharenting não transgride apenas o direito à imagem, que "[...] desfruta de autonomia e, por isso, sua proteção não depende da violação de outro direito" (FACHIN, 2001, p. 191), mas também a própria esfera da vida privada, bens jurídicos que auxiliam os infantojuvenis no seu processo de autodeterminação como pessoa. Isso porque

\begin{abstract}
o direito à própria imagem, mesmo que as crianças não possam exercê-los em um primeiro momento de maneira autônoma, a necessitar de seus representantes legais, incluiu a imagem em si, bem como a voz da pessoa. É um componente da privacidade e visa proteger a identidade, a atmosfera íntima, relações pessoais e até mesmo a libertação sexual. É ela que torna as pessoas únicas e as distingue de outras pessoas, de forma que se deve ter o controle da própria imagem e, portanto, de uma eventual publicidade sobre ela (KISS, 2017, p. 167, tradução nossa) 9
\end{abstract}

Dessa forma, observa-se que a imagem é um dos meios pelos quais a personalidade se manifesta, essencial para a formação da individualidade das crianças e dos adolescentes. Por conseguinte, "ao permitirem a exposição da imagem do filho, cabe aos pais zelar para que a publicação ocorra de forma positiva, contribuindo para o perfeito desenvolvimento da sua personalidade infanto-juvenil" (CURY JÚNIOR, 2006, p. 206).

Atrelando-se, sobretudo, aos princípios da parentalidade responsável, melhor interesse da criança e do adolescente e dignidade da pessoa humana, visto que a inobservância desses pode vir a causas alguns prejuízos que serão discorridos em seguida.

\title{
3 POSSÍVEIS CONSEQUÊNCIAS JURÍDICAS DO SHARENTING
}

O sharenting é característico da Era Digital e também do fato de que há uma superexposição de crianças e adolescentes pelos próprios pais nas mídias sociais. Apesar dessa ampla divulgação, poucos genitores sabem dos reais impactos que podem vir a causar na vida de seus filhos, isto porque, consoante os ensinamentos de Fernando Büscher von Teschenhausen Eberlin (2017), eles possuem pouco conhecimento a respeito da Sociedade de

\footnotetext{
${ }^{9}$ The right to one 's own image, including the protection of image and voice of the person, is a component of privacy and seeks to protect the identity, intimate sphere, personal relationships, or sexual liberation of it. A person's image constitutes one of the chief attributes of his or her personality, as it reveals the person's unique characteristics and distinguishes the person from his or her peers. The right to the protection of one's image is thus one of the essential components of personal development. It mainly presupposes the individual's right to control the use of that image, including the right to refuse publication.
} 
Informação, que é pautada, sobretudo, pela coleta e armazenamento de dados. Reconhece-se que

neste novo cenário que se estabelece as relações entre indivíduos se mostram mais intensas, na procura de exteriorizar a vida privada e tornar público a vida íntima na expectativa de informar a sociedade da felicidade plena existente no foro íntimo de cada indivíduo (PEREIRA, 2015, p. 04).

Vale ressaltar que, a exposição em demasiado e sem filtro pode colocá-los em situações vexatórias e constrangedoras que tem o condão de causar prejuízos à integridade psíquica, podendo acompanhá-los pelas etapas da vida e, inclusive, influenciar na dinâmica familiar e, a depender do caso, no comportamento das crianças e adolescentes até mesmo com outros agrupamentos humanos.

A veiculação de imagens em ambientes virtuais, sem restrições, é hábil para que pessoas possam capturá-las e utilizá-las com outros destinos sem a autorização dos responsáveis legais, além de poder causar vitimização por cyberbullying. Sendo assim,

[...] os pais devem considerar o efeito geral que o compartilhamento tem no desenvolvimento psicológico de uma criança. As crianças se moldam no comportamento de seus pais e, quando estes compartilham constantemente, monitorando sua conta nas redes sociais por likes e seguidores e buscando reconhecimento através disto, elas percebem. Quando as crianças veem seus pais compartilhando informações pessoais na esfera pública, elas provavelmente receberão a mensagem de que uma abordagem pública para compartilhar detalhes pessoais sobre suas vidas é esperada e apropriada. A super exposição do adolescente pode criar problemas para a sua reputação no futuro (STEINBERG, 2017, p. 882, tradução nossa $)^{10}$.

Ressalta-se que a responsabilidade parental encontra seus limites nos próprios direitos fundamentais e da personalidade dos filhos. De modo que deve ser praticado com o fim de proporcionar um ambiente saudável e capaz de ajudar na construção da personalidade das crianças e dos adolescentes. Assim, o "[...] o princípio da autonomia familiar proporciona aos pais a liberdade no exercício do poder familiar, a legitimidade desse exercício está condicionada ao respeito dos direitos fundamentais dos filhos" (DELGADO, 2005, p. 42).

\footnotetext{
${ }^{10}[$...] parents must consider the overall effect sharing has on a child's psychological development. Children model the behavior of their parents, and when parents constantly share milestones, monitor their social media accounts for likes and followers, and seek out recognition for what was once considered mundane daily life, children take note. [...] When children see their parents sharing personal information in the public sphere, they will likely get the message that a public approach to sharing personal details about their lives is expected and appropriate. Oversharing in adolescence can create issues for the child's reputation on into the future.
} 
No entendimento de Ramos (2015, p. 43), na atualidade, a concepção do poder familiar é instrumental e democrática, funcionalizada para a promoção e desenvolvimento da personalidade do filho, visando à sua educação e criação de forma participativa, com respeito à sua individualidade e integridade biopsíquica, e, sobretudo, pautada no afeto.

Ademais, levando em consideração o caso de sharenting, pode haver consequências jurídicas aos pais dos vulneráveis. Vislumbra-se que, nos casos de abuso do poder parental, a autoridade judiciária, a requerimento de algum parente ou do próprio Ministério Público, aplicará medida de proteção ${ }^{11}$ visando à salvaguarda da criança ou adolescente. Inclusive, poderá culminar na suspensão do poder familiar (art. 1637 do Código Civil). Pode ocorrer, ainda, a hipótese de gerar a destituição do poder familiar, em especial a prática de atos contrários à moral e aos bons costumes (inciso II do art. 1638 do Código Civil).

Nesse contexto, importante frisar que os textos do Código Civil e do Estatuto da Criança e do Adolescente asseguram à criança e ao adolescente o acesso à justiça mesmo quando seus interesses colidem com os de seus responsáveis legais ${ }^{12}$, o que demonstra a preocupação do legislador com o público infantojuvenil a partir da adoção da teoria da proteção integral.

Aliás, fala-se ainda na possibilidade de reparação civil pelos danos causados em virtude do sharenting. "Os remédios específicos e tradicionais do Direito de Família têm se mostrado insuficientes [...] A Responsabilidade Civil, como remédio geral e irrestrito, tornouse naturalmente a esperança para onde convergiram todos esses anseios" (SCHREIBER, 2015, p. 32).

Vale registrar que parece não ter ainda ocorrido no Brasil casos de pais que foram responsabilizados civilmente pela divulgação de imagens, informações e dados dos filhos de maneira reiterada nas redes sociais, com a ressalva feita por Amanda de Cássia Pereira Coutinho $(2019$, p. 51) de que talvez a geração afetada pelo fenômeno seja demasiadamente jovem para tomar medidas legais contra seus progenitores, o que poderá vir a acontecer quando alcançarem a fase adulta.

Vale ressaltar que este trabalho não defende a absoluta proibição de exposição dos filhos nas mídias sociais, até porque a titularidade do poder familiar pertence aos genitores, todavia o que se pretende é frisar o compartilhamento responsável.

\footnotetext{
${ }^{11}$ Ler o art. 129 do ECA.

${ }^{12}$ Ler também o parágrafo único do art. 141 do ECA.
} 
Entende-se "como dever prioritário e fundamental, devem os genitores antes de tudo, assistir seus filhos, no mais amplo e integral exercício de proteção, [...] mantê-los sob a sua guarda, segurança e companhia, e zelar por sua integridade moral e psíquica" (MADALENO, 2019, p. 736).

Neste sentido, demasiado significativo relembrar o atual entendimento da criança e do adolescente pelo ordenamento jurídico brasileiro, balizado pela doutrina na teoria da proteção integral, nos infantojuvenis como sujeitos de direitos, de forma que não estão irrestritamente subordinados à responsabilidade parental. Questiona-se ainda,

\begin{abstract}
como saber se a exposição mediática, publicação de fotos e vídeos íntimos está a causar-lhes sofrimento em vez de entretenimento, se muitas vezes esta criança sequer foi ouvida, e ainda assim, precisa de continuar a ser mantida calada dentro da mesma relação afetiva com as pessoas de referência que fazem a partilha da sua vida, ou melhor, expõem, postam e dispõe da sua vida privada, sem indagações, pareceres psicológicos ou conhecimento de danos traumáticos que a exposição possa vir a desenvolver? (COUTINHO, 2019, p. 43).
\end{abstract}

Portanto, crianças e adolescentes são verdadeiros sujeitos de direitos, logo, é essencial que, assim que possível, suas vontades sejam levadas em consideração. Nesse liame, a autonomia de vontade, de acordo com Santa Rosa, Corte-Real e Vieira (2013, p. 638) se corresponde " [...] ao progressivo desenvolvimento de uma consciência crítica dialógica, sendo um dos pressupostos básicos da convivência de sujeitos autônomos tomar o outro não como um objeto, mas como um sujeito que tem algo a dizer".

Por fim, reconhece-se que a exibição dos filhos nas redes sociais deve ser feita de modo ponderado e consciente, de maneira que é de incumbência dos genitores prezarem por criá-los em uma esfera saudável, conduzidos pelo melhor interesse da criança e do adolescente, parentalidade responsável e, sobretudo, dignidade da pessoa humana.

\title{
CONCLUSÃO
}

Formar um núcleo familiar não é apenas realizar a continuidade de sua linhagem, particularmente em razão de, na contemporaneidade, a família ter assumido novo papel. Logo, passou-se a levar em consideração não apenas os vínculos biológicos, mas a afetividade em si, que, nos dias atuais, é um princípio de grande valia para o direito das famílias.

A família não é mais formada tão somente pelo matrimônio, reconhecendo-se outras formas de família e cada vez mais a doutrina e a jurisprudência protegem novos formatos, 
que, eventualmente, poderão vir a serem abarcados pela legislação. O fato é que à família cabe a responsabilidade de projetar os instrumentos necessários a fim de que seus membros alcancem os objetivos que os realizem. Para isso, certos princípios englobam essas estruturas multicelulares e ajudam para que isto seja possível.

Nesse estudo, deu-se especial atenção aos princípios do melhor interesse da criança, do adolescente e do jovem e da parentalidade responsável, ambos essenciais para o resguardo dos direitos dos infantojuvenis, porém que não são observados em certas circunstâncias, como o fenômeno retratado neste estudo.

O sharenting, fenômeno típico da Era Digital, é caracterizado pela exposição excessiva de imagens, dados e informações dos filhos pelos próprios genitores nas mídias sociais, sendo que estes, na maioria das vezes, não têm conhecimento das consequências que a superexposição desse grupo pode gerar, especialmente em relação aos danos à imagem, um fator que contribuiu para a individualidade do ser humano.

Além de ter o condão de comprometer o desenvolvimento saudável de crianças e de adolescentes, consequências legais podem advir desse fenômeno, chegando, em casos mais graves, até mesmo a suspensão ou perda do poder familiar, haja vista que este não é um poder ilimitado, devendo sempre ser observado o melhor interesse dos filhos, os quais são verdadeiros sujeitos de direitos.

Portanto, os genitores devem se utilizar das redes sociais de maneira diligente, a demonstrarem afeto para com seus filhos e cuidado com o crescimento pessoal, assim como devem prezar pelo desejo desses de serem exibidos ou não, pois a imagem é a própria externalização da individualidade do ser e imprescindível para a formação humana.

\section{REFERÊNCIAS}

BRASIL. [Constituição (1988)]. Constituição da República Federativa do Brasil de 1988. Brasília, DF: Presidência da República, [2020]. Disponível em:

http://www.planalto.gov.br/ccivil_03/constituicao/constituicao.htm. Acesso em: 4 jul. 2020.

BRASIL. Lei no 10.406, de 10 de janeiro de 2002. Institui o Código Civil. Brasília, DF: Presidência da República, [2019]. Disponível em: http://www.planalto.gov.br/ccivil_03/leis/2002/110406.htm. Acesso em: 4 jul. 2020. 
BRASIL. Lei no 8.069, de 13 de julho de 1990. Dispõe sobre o Estatuto da Criança e do Adolescente e dá outras providências. Brasília, DF: Presidência da República, [2019]. Disponível em: http://www.planalto.gov.br/ccivil_03/leis/18069.htm. Acesso em: 4 jul. 2020.

BRASIL. Lei n ${ }^{\circ}$ 6.515, de 26 de dezembro de 1977. Regula os casos de dissolução da sociedade conjugal e do casamento, seus efeitos e respectivos processos, e dá outras providências. Brasília, DF: Presidência da República. Disponível em:

http://www.planalto.gov.br/ccivil_03/leis/16515.htm. Acesso em: 4 jul. 2020.

BRASIL. Decreto n ${ }^{\circ} 99.710$, de 21 de novembro de 1990. Promulga a Convenção sobre os Direitos da Criança. Brasília, DF: Presidente da República. Disponível em: http://www.planalto.gov.br/ccivil_03/decreto/1990-1994/d99710.htm. Acesso em: 18 jul. 2020.

CALDERÓN, R. Princípio da afetividade no direito de família. Rio de Janeiro: Renovar, 2013. Disponível em:

http://www.egov.ufsc.br/portal/sites/default/files/principio_da_afetividade_no_direito_de_fa milia.pdf. Acesso em: 07 jul. 2020.

CARDIN, V. S. G.; GUERRA, M. G. R. M.; SANTOS, A. C. G. G. Dos reflexos da crise do direito liberal na atualidade quando do exercício da parentalidade responsável. Revista Direito e Justiça - Reflexões sociojurídicas. [s. 1.], ano XVI, n. 23, p. 131-148, nov. 2014. Disponível em: file:///C:/Users/Usuario/AppData/Local/Temp/1526-4807-1-PB-2.pdf. Acesso em: 14 jul. 2020.

CARDIN, V. S. G.; ROSA, L. C. B. Da realização do projeto homoparental por meio da utilização da reprodução humana assistida. In: Encontro Nacional do CONPEDI, 21, 2012, Uberlância. Artigos [...]. Uberlândia, MG, 2012. Disponível em:

http://www.publicadireito.com.br/artigos/?cod=d516b13671a4179d. Acesso em: 11 jul. 2020.

CIRIBELI, J. P.; PAIVA, V. H. P. Redes e mídias sociais na internet: realidades e perspectivas de um mundo conectado. Mediação. Belo Horizonte, v. 13, n. 12, p. 59-74, jan./jun. 2011. Disponível em: file://C:/Users/Usuario/AppData/Local/Temp/509-518-1-SM1.pdf. Acesso em: 15 jul. 2020.

COUTINHO, A. de C. P. A proteção da reserva da vida privada de menores enquanto dever parental, em especial na era digital. 2019. 61 f. Dissertação (Mestrado em Ciências jurídicaspolíticas) - Faculdade de Direito, Universidade de Lisboa, Lisboa, 2019. Disponível em: https://repositorio-aberto.up.pt/bitstream/10216/126141/2/384898.pdf. Acesso em: 11 jul. 2020. 
CUSTÓDIO, A. V. Teoria da proteção integral: pressuposto para compreensão do direito da criança e do adolescente. Revista do Direito: UNISC. Santa Cruz do Sul, RS, n. 29, p. 22-43, jan./jun. 2008. Disponível em:

https://online.unisc.br/seer/index.php/direito/article/viewFile/657/454. Acesso em: 5 jun. 2020 .

CURY JÚNIOR, D. A proteção jurídica da imagem da criança e do adolescente. 2006. 284 f. Tese (Doutorado em Direito das Relações Sociais), Pontifícia Universidade Católica de São Paulo, São Paulo, 2006. Disponível em:

http://www.dominiopublico.gov.br/download/teste/arqs/cp011640.pdf. Acesso em: 10 jun. 2020.

DIAS, J. S. O direito à imagem. Belo Horizonte: Del Rey, 2000.

DELGADO, M. L. Direitos da personalidade nas relações familiares. In: Congresso Brasileiro de Direito de Família, 5, 2005, Belo Horizonte. Anais [...]. Belo Horizonte: Instituto Brasileiro de Direito de Família (IBDFAM), 2005, p. 1-57. Disponível em: http://www.ibdfam.org.br/_img/congressos/anais/34.pdf. Acesso em: 14 jul, 2020.

EBERLIN, F. B. von T. Sharenting, liberdade de expressão e privacidade de crianças no ambiente digital: o papel dos provedores de aplicação no cenário jurídico brasileiro. Revista brasileira de políticas públicas. [s. 1.], v. 7, n. 3, p. 256-274, dez. 2017. Disponível em: file:///C:/Users/Usuario/AppData/Local/Temp/4821-21861-10-PB-1.pdf. Acesso em: 07 jul. 2020 .

FACHIN, Z. A. Informação, Imagem e Princípio da Proporcionalidade. UNOPAR Científica Ciências Jurídicas e Empresariais. Londrina. v. 2. n. 1. p. 189-195, mar. 2001. Disponível em: https://revista.pgsskroton.com/index.php/juridicas/article/view/1592. Acesso em: 08 jun. 2020.

FACHIN, Z. A. A proteção jurídica da imagem. São Paulo: Celso Bastos Editor: Instituto Brasileiro de Direito Constitucional, 1999.

JABORANDY, C. C. M.; GOLDHAR, T. G. M. A repersonalização do direito civil a partir do princípio da fraternidade: um novo enfoque para tutela da personalidade na contemporaneidade. Revista Jurídica Cesumar. Maringá, PR, v. 18, n. 2, p. 481-502, maio/ago. 2018. Disponível em: file:///C:/Users/Usuario/AppData/Local/Temp/6267Texto\%20do\%20artigo\%20-\%20Arquivo\%20Original-30323-1-10-20180828.pdf. Acesso em: 10 jul. 2020. 
KISS, I. Protection of children's right to personal portrayal. Fiat Iustitia. [s. 1.], n. 1, p. 167183, 2017. Disponível: https://ideas.repec.org/a/dcu/journl/v11y2017i1p166-183.html. Acesso em: 5 jun. 2020.

LISBOA, R. S.; CHRISTÓFARO, D. F. Sociedade da informação: dano e responsabilidade civil decorrente da prática de sharenting. In: Encontro Nacional do CONPEDI. 27, 2018, Salvador. Publicações [...]. Salvador, BA, 2018. Disponível em: http://conpedi.danilolr.info/publicacoes/0ds65m46/41oo8qd1/QfIJXdcms7SfNjh2.pdf. Acesso em: 13 jul. 2020.

LÔBO, P. Direito civil: famílias. São Paulo: Saraiva, 2016. ISBN 9788547209865.

Disponível em:

https://search.ebscohost.com/login.aspx?direct=true \&db=edsmib\&AN=edsmib.000010792 $\langle=$ pt-br\&site=eds-live. Acesso em: 13 jun. 2020.

MADALENO, R. Direito de família. Rio de Janeiro: Forense, 2019. ISBN 9788530987961. Disponível em:

https://search.ebscohost.com/login.aspx?direct=true \&db=edsmib\&AN=edsmib.000015804〈= pt-br\&site=eds-live. Acesso em: 24 jun. 2020.

MANDELLI, M. Caso 'Bel para Meninas' e a exposição infantil nas redes. Educamídia. [s. 1.], 28 maio. 2020. Disponível em: https://educamidia.org.br/caso-bel-para-meninas-e-aexposicao-infantil-nas-redes/. Acesso em: 08 jul. 2020.

MARZAGÃO, S. F. O 'sharenting' e os filhos de pais separados. Estadão. [s. 1.], 14 maio. 2019. Disponível em:

https://www.google.com/url?sa=t\&rct=j\&q=\&esrc=s\&source=web\&cd=\&cad=rja\&uact=8\&v ed=2ahUKEwiI2rXZ7tvqAhUwHbkGHe1_CjcQFjAAegQIBBAB\&url=https\%3A\%2F\%2Fp olitica.estadao.com.br\%2Fblogs $\% 2$ Ffausto-macedo $\% 2$ Fo-sharenting-e-os-filhos-de-paisseparados\%2F\&usg=AOvVaw38zE2dzMKTPw89P_gtmsTz. Acesso em: 8 jul. 2020.

MARÍN, J. Á. J. La era digital: nuevos médios, nuevos usuários y nuevos profesionales. Razón y palabra: primera revista electrónica en América Latina especializada em comunicación. [s. 1.], n. 71, p. 1-11, 2007. Disponível em: http://www.razonypalabra.org.mx/N/N71/VARIA/29\%20JODAR_REVISADO.pdf. Acesso em: 08 jul. 2020.

MORAES, C. A. Responsabilidade civil dos pais na reprodução humana assistida. São Paulo: Método, 2019. 
OLIVEIRA, A. da C. Implicações da doutrina da proteção integral na consideração das crianças e dos adolescentes como pessoas em desenvolvimento. In: Congresso Nacional do CONPEDI, 17, 2008, Brasília. Anais [...]. Brasília, DF, 2008. Disponível em: http://www.publicadireito.com.br/conpedi/manaus/arquivos/anais/brasilia/05_887.pdf. Acesso em: 10 jul 2020.

PERASSO, V. O que é a $4^{\mathrm{a}}$ revolução industrial - e como ela deve evitar nossas vidas. BBC News Brasil. [s. 1.], 22 out. 2016. Disponível em: https://www.bbc.com/portuguese/geral37658309. Acesso em: 09 jul. 2020.

PEREIRA, M. do N. 2015. A superexposição de crianças e adolescentes nas redes sociais: necessária cautela no uso das novas tecnologias para a formação de identidade. In: Congresso Ibero-Americano de Investigadores e Docentes de Direito e Informática - Rede CIIDDI, 5, Santa Maria. Anais[...]. Santa Maria: UFSM, 2015, p. 1-13. Disponível em: http://coral.ufsm.br/congressodireito/anais/2015/6-14.pdf. Acesso em: 05 jun. 2020.

RAMOS, P. P. de O. C. Poder familiar e a guarda compartilhada: novos paradigmas do direito de família. São Paulo: Saraiva, 2015. ISBN 9788502637306. Disponível em: https://search.ebscohost.com/login.aspx?direct=true \&db=edsmib\&AN=edsmib.000008943<= pt-br\&site=eds-live. Acesso em: 12 jul. 2020.

RIBEIRO, L. Família se defende das denúncias de "Salve Bel para meninas": "Muitas estórias são de ficção". Extra. [s. 1.], 21 maio. 2020. Disponível em: https://extra.globo.com/tv-elazer/familia-se-defende-das-denuncias-de-salve-bel-para-meninas-muitas-estorias-sao-deficcao-rv1-1-24438295.html. Acesso em: 08 jul. 2020.

ROSSATO, L. A. Estatuto da Criança e do Adolescente : Lei n. 8.069/90: comentado artigo por artigo. São Paulo: Saraiva, 2019. ISBN 9788553608386. Disponível em:

https://search.ebscohost.com/login.aspx?direct=true\&db=edsmib\&AN=edsmib.000014194/= pt-br\&site=eds-live. Acesso em: 23 mar. 2021.

ROSSATO, L. A.; LÉPORE, P. E.; CUNHA, R. S. Estatuto da criança e do adolescente (lei 8.069/1990): comentado artigo por artigo. 6. ed. São Paulo: Revista dos Tribunais, 2014.

SANTA ROSA, B.; CORTE-REAL, F.; VIEIRA, D. N. O respeito pela autonomia da criança na regulação das responsabilidades parentais. Revista Científica da Ordem dos Médicos: Acta Médica Portuguesa. [s. 1.], v. 26, n. 6, p. 637-643, nov./dez. 2013. Disponível em: https://www.google.com/url?sa=t\&rct=j\&q=\&esrc=s\&source=web\&cd=\&ved=2ahUKEwiP5 LGgpdzqAhXwGbkGHYtbABYQFjAAegQIBRAB\&url=https\%3A\%2F\%2Fwww.actamedic aportuguesa.com $\% 2$ Frevista $\% 2$ Findex.php $\% 2$ Famp $\% 2$ Farticle $\% 2 F d o w n l o a d \% 2 F 4050 \% 2 F 3$ 801\&usg=AOvVaw3j1g0uVX8sDbmHqY1sB3jG. Acesso em: 16 jul. 2020. 
SARAIVA, J. B. C. Adolescente em conflito com a lei: da indiferença à proteção integral. 3. ed. Porto Alegre: Livraria do Advogado Editora, 2009.

SCHREIBER, A. Direitos da personalidade: revista e atualizada. São Paulo: Atlas, 2014. ISBN 9788522493449. Disponível em: https://search.ebscohost.com/login.aspx?direct=true\&db=edsmib\&AN=edsmib.000006119<= pt-br\&site=eds-live. Acesso em: 11 jul. 2020.

SILVA, R. L. da. Adolescentes on-line: o ciberespaço como um ambiente de promoção dos direitos humanos. In: PES, J. H. F (coord.). Direitos humanos: crianças e adolescentes. Curitiba: Juruá Editora, 2012.

STEINBERG, S. B. Sharenting: Children's Privacy in the Age of Social Media. Emory Law Journal. Atlanta, v. 66, p. 839-889, 2017. Disponível em:

http://scholarship.law.ufl.edu/cgi/viewcontent.cgi?article=1796\&context=facultypub. Acesso em: 05 jul. 2020.

TEPEDINO, G. Fundamentos de direito civil, v. 6: direito de família. Rio de Janeiro: Forense, 2020. ISBN 9788530989965. Disponível em:

https://search.ebscohost.com/login.aspx?direct=true $\& d b=$ edsmib \&AN=edsmib. $000017770<=$ pt-br\&site=eds-live. Acesso em: 12 jul. 2020. 